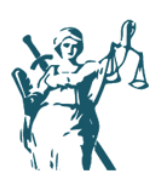

JUSTICIA

ISSN impreso 0124-7441

\title{
La amigable composición: el carácter de la decisión, su impugnación y ejecución.
}

\section{The friendly composition: the character of the decision, its challenge and execution.}

\author{
Marcela Rodríguez Mejía \\ Universidad Externado, Colombia \\ marcelar.rodriguez@uexternado.edu.co
}

Recibido: 10 de agosto de 2019 / Aceptado: 05 de octubre de 2019

https://doi.org/10.17081/just.24.36.3767

\section{Resumen}

El objetivo de este artículo de investigación es responder a la pregunta de investigación de si la amigable composición, tal y como hoy en día se encuentra regulado en el Estatuto Arbitral, es un mecanismo eficiente para resolver controversias. Con ese objetivo en mente, se estudian y analizan tres cuestiones: cuál es el carácter de la decisión emitida por un amigable componedor; cómo se ejecuta esa decisión y con qué mecanismos de contradicción puede atacarse la misma. Para resolver estos interrogantes, y utilizando el método hermenéutico -siempre de forma crítica-, se estudian e interpretan las tres normas de la Ley 1563 de 2012 que regulan la amigable composición, y las disposiciones del Código Civil que hacen lo propio con la transacción; primero de forma individual, y luego, debido al símil que la primera de estas normas hace a la transacción, de forma comparada.

Palabras Clave: amigable composición; transacción; ejecución; cosa juzgada.

\begin{abstract}
The objective of this research article is to answer the research question of whether the friendly composition, as it is currently regulated in the Arbitration Statute, is an efficient mechanism to resolve disputes. With that goal in mind, three issues are studied and analyzed: what is the nature of the decision issued by a friendly composer; how that decision is executed and with what mechanisms of contradiction it can be attacked. To solve these questions, and using the hermeneutical method - always critically - the three norms of Law 1563 of 2012 that regulate the friendly composition, and the provisions of the Civil Code that do the same with the transaction are studied and interpreted; first individually, and then, due to the similarity that the first of these rules makes to the transaction, in a comparative way.
\end{abstract}

Keywords: friendly composition; transaction; execution; res judicata.

Como citar:

Rodríguez Mejía, M. (2019). La amigable composición: el carácter de la decisión, su impugnación y ejecución. Una revisión crítica de la figura. Justicia, 24(36), 229-239. https://doi.org/10.17081/just.24.36.3767

Justicia Vol. 24 No. 36: pp. 229-239. Julio - diciembre, 2019. DOI: 10.17081/just.24.36.3767

(c) Copyright 2019 by Rodríguez Mejía, M

open 2 access (c) (i) 


\section{INTRODUCCIÓN.}

Todo aquel que estudie el Estatuto de Arbitraje Nacional e Internacional de Colombia se sorprenderá cuando encuentre en medio de este, entre el régimen del arbitraje nacional y el internacional, la figura de la amigable composición regulada en tres artículos que dicen definirla, fijar sus efectos, establecer cómo se debe elegir al amigable componedor, y el procedimiento que debe surtirse en cada amigable composición (artículos 59 al 61 Ley 1563 de 2012).

Desde la expedición del Estatuto Arbitral, aunque de forma lenta, la amigable composición se ha venido abriendo paso entre los sujetos negociales que operan en Colombia, que por el propio devenir de sus negocios se ven abocados a un conflicto que deba ser resuelto por las vías del derecho. Sin embargo, y quizás debido a su particular ubicación la una ley 1563 de 2012, que desde su propio título da a entender que regula otra figura -Estatuto Arbitral-, no la amigable composición, muy poco se ha escrito en la doctrina sobre esta.

Es pues lo reciente de esta figura y los pocos estudios que hay sobre la misma las razones por las que se ha elegido estudiar esta figura y posteriormente escribir este artículo de investigación.

Tres han sido las cuestiones objeto de análisis en este artículo: i) la naturaleza jurídica de la decisión del amigable componedor; ii) si puede o no ser objeto de impugnación; y iii) cómo es su ejecución. Todas ellas necesarias para resolver la pregunta de investigación que al final de este artículo pretendemos resolver: ¿la amigable composición es un mecanismo de resolución efectiva eficaz?

\section{METODOLOGÍA}

Para alcanzar los objetivos propuestos se utilizó una metodología hermenéutica. En concreto, se analizaron las disposiciones de la Ley 1563 de 2012 que regulan la amigable composición y las que hacen lo propio con la transacción en el Código Civil.

La ausencia de citas obedece a que la búsqueda de bibliografía y jurisprudencia especializada sobre el tema de esta investigación no arrojó ningún resultado debido a la falta de investigaciones que a la fecha se han desarrollado en el país sobre la materia. Hasta ahora, la amigable composición ha sido un tema tratado de forma tangencial en las manuales de derecho procesal.

\section{NATURALEZA JURÍDICA DE LA DECISIÓN DEL AMIGABLE COMPONEDOR}

La razón por la cual se hace necesario estudiar la naturaleza jurídica de una figura jurídica es porque ello nos indica qué es la figura y nos permite comprender cómo serán sus relaciones con las distintas instituciones también jurídicas.

Justicia Vol. 24 No. 36: pp. 229-239. julio - diciembre, 2019. DOI: 10.17081/just.24.36.3767 
Así las cosas, en el caso de la decisión del amigable componedor, conocer cuál es su naturaleza jurídica es indispensable para alcanzar los objetivos específicos que se propone este artículo: i) definir si es o no posible, y cómo, oponerse a la decisión del amigable componedor; y ii) resolver cuál es la vía para ejecutar la misma; todos ellos necesarios para resolver la pregunta de investigación del mismo.

\section{La decisión del amigable componedor goza de los mismos efectos que una transacción. Significado}

El mandato del artículo 60 de la Ley 1563 de 2012 "La decisión del amigable componedor producirá los efectos legales propios de la transacción", significa que tal decisión se regirá por las normas de la transacción. Es decir, es la propia regulación de la amigable composición la que renuncia a definir la regulación de su propia decisión al extrapolar lo que pase con la misma a una figura ajena: la transacción.

Así las cosas, para conocer qué efectos tiene, cómo puede objetarse y cómo ejecutarse, se hace necesario revisar dentro del catálogo de disposiciones que en el Código Civil regulan la transacción (artículos 2469 a 2487), aquellas que hacen referencia al contrato mismo que resulta de lo transado.

\section{Cosa juzgada}

El artículo 2883 del Código Civil que expresamente regula cuáles serán los efectos de toda transacción, dice: "produce el efecto de cosa juzgada en última instancia".

Así las cosas, habrá que entender que la decisión del amigable componedor tiene efectos de cosa juzgada en última instancia, lo que se traduce en la inexistencia de algún recurso ordinario o extraordinario que permitan atacar y modificar dicha decisión.

\section{Objeto de anulación y rescisión}

El mismo artículo 2883 del Código Civil antes mencionado, continúa en su redacción con la conjunción adversativa pero, señalando que contra la transacción "podrá impetrarse la declaración de nulidad o la rescisión". Es decir, lo que dicho artículo viene a decir es que a pesar de que se entiende que contra la transacción no procede ningún recurso porque produce los efectos de cosa juzgada de última instancia, contra ella si puede intentarse la nulidad y la rescisión ${ }^{1}$.

Pues bien, trasladando esto al ámbito de la amigable composición, teniendo en cuenta que la voluntad del legislador fue que la decisión del amigable componedor tenga los efectos de la transacción, es obligatorio concluir que contra la decisión del amigable componedor procede la anulación y la rescisión.

\footnotetext{
${ }^{1}$ Con ello el legislador pretende evitar que la transacción no tenga ningún tipo de control por parte de quien administra justicia. Al mismo tiempo, con ello se busca proteger a aquel que pudiera verse afectado con una transacción.
}

Justicia Vol. 24 No. 36: pp. 229-239. julio - diciembre, 2019. DOI: 10.17081/just.24.36.3767 


\section{OPOSICIÓN A LA DECISIÓN DEL AMIGABLE COMPONEDOR}

Tal y como se señalaba supra, la decisión del amigable componedor podrá ser anulada y rescindida, conforme las causales contempladas en el Código Civil para la transacción.

\section{La nulidad de la transacción, ergo de la decisión del amigable componedor}

El Código Civil recoge a partir del artículo 2477 y hasta el 2480, cinco supuestos que de configurarse conllevarían la nulidad de la transacción. Estas son: a) respecto el título sobre el que pudo haber recaído la transacción, esta será nula cuando se obtenga por títulos falsificados o nulo ${ }^{2}$; b) en torno a las circunstancias que rodearon la transacción, será nula aquella en la que se ejerció dolo o violencia ${ }^{3}$ o sobre una controversia que al momento de la transacción ya se hubiera resuelto por sentencia ${ }^{4}$; y, finalmente, c) será nula la transacción cuando haya habido error en la identidad del objeto sobre el que se quiere transigir ${ }^{5}$.

Siendo que el artículo 59 de la Ley 1563 de 2012 obliga entender la decisión del amigable componedor, en lo que a sus efectos se refiere, como una transacción, y que una de las consecuencias de esta es precisamente la posibilidad de ser anulada cuando se configure uno de los motivos antes señalados, debe analizarse si los mismos podrían o no configurarse en sede de la amigable composición para así resolver cuándo podría intentarse la anulación de la decisión de la amigable composición por aplicación analógica de las normas del Código Civil sobre la anulación de la transacción.

\section{La nulidad por el título}

En torno al título sobre el que recayó la transacción, el artículo 2477 del Código Civil referido anteriormente consagra dos posibles defectos que de recaer en el título tornarán la transacción anulable, estos son la falsedad y la nulidad de este.

Sin duda, tanto la falsedad del título como su nulidad son situaciones que pueden presentarse cuando el título sea objeto de controversia en una amigable composición; es decir, no son defectos que solo afectan a los títulos objeto de transacción, por ende la conclusión no puede ser otra que la de entender que esta es una causal para atacar en anulación la decisión del amigable componedor.

La nulidad por dolo o violencia

\footnotetext{
${ }^{2}$ Artículo 2477 CC.

${ }^{3}$ Artículo 2476 CC.

${ }^{4}$ Artículo 2478 CC.

${ }^{5}$ Artículo 2480 CC.
}

Justicia Vol. 24 No. 36: pp. 229-239. julio - diciembre, 2019. DOI: 10.17081/just.24.36.3767 
Acerca de las circunstancias que rodearon la transacción, el Código Civil sanciona con nulidad aquella que resulta de una situación de dolo o violencia.

Aunque la norma no de detalles en torno a esta situación se ha entendido que la misma ocurre cuando uno de los sujetos en el contrato de transacción forzó a su contraparte a transar, limitando el derecho de libertad contractual a esta.

Si trasladamos esta situación a la amigable composición, lo primero que hay que tener en cuenta es que estamos hablando en una vía para resolver controversias donde no solo están presentes las partes del contrato -como en una transacción-, sino también quien resuelve la controversia, el amigable componedor; este trinomio de sujetos hace necesario analizar contra quien podría ejercerse la violencia y el dolo para que se configure este causal: ¿contra las partes involucradas en el conflicto?; o ¿contra el amigable componedor?

La primera hipotesis, violencia o dolo ejercido por una parte contra otra sí podía darse y configuraría el mismo supuesto que se plantea en la transacción: una parte ejerce violencia o dolo sobre otra para que suscriba, en este caso concreto, un acuerdo de resolver su conflicto por la vía de la amigable composición.

La segunda hipotesis, violencia o dolo ejercido por las partes contra el amigable componedor, aunque de difícil configuración, sí podría llegar a darse, y por tanto, debe ser sancionada por el ordenamiento. Piénsese en el caso que se presenta cuando ambas partes se confabulan para coaccionar a un amigable componedor. Sin embargo, esta hipotesis no debe ser sancionada con la anulación, porque no tendría ningún sentido que el propio componedor intentara la anulación de su decisión ${ }^{6}$.

La nulidad porque la controversia ya había sido resuelta

Conforme el artículo 2478 del Código Civil una transacción será nula "si, al tiempo de celebrarse, estuviere ya terminado el litigio por sentencia pasada en autoridad de cosa juzgada, y de que las partes o alguna de ellas no haya tenido conocimiento al tiempo de transigir".

El supuesto de esta norma también puede presentarse cuando se está hablando de una amigable composición; puede ocurrir, perfectamente, que se surta una amigable composición cuando ya el litigio fue resuelto mediante sentencia.

\section{La nulidad por la identidad del objeto}

Siempre que haya existido error en la identidad del objeto, la transacción es susceptible de ser anulada (artículo 2480 del Código Civil). Tal error también puede presentarse en sede de la amigable composición, y aunque con menos probabilidad teniendo en cuenta que allí está el componedor quien podrá percatarse oportunamente de aquel- de configurarse podrá dar lugar a la anulación.

\footnotetext{
${ }^{6}$ Se entiende que el componedor, en caso de que no hubiera podido plantear el acoso y la violencia
} sufrida durante el trámite, deberá acudir a las vías penales. 


\section{La rescisión de la transacción, ergo de la decisión del amigable componedor}

Junto con la anulación, la rescisión es un control que el legislador le ha impuesto a la transacción. De acuerdo con el Código Civil la transacción se podrá rescindir en dos eventos: i) cuando habiéndose creído transigir con una persona, resulta que se efectúo tal contrato con otra ${ }^{7}$; y ii) cuando se demuestre que una de las partes de la transacción no tenía ningún derecho sobre el objeto sobre el que versó la transacción.

A continuación, y teniendo en cuenta la naturaleza jurídica de la decisión de la amigable composición, se analizarán las anteriores causales a la luz de esa decisión, con el fin de determinar cómo sería su aplicación a esta.

\section{Rescisión por error en la persona}

Esta causa legal responde a aquellos eventos en los que la persona con la que se creía haber transado, resulta ser otra. En otras palabras, el supuesto fáctico que genera la norma es que se trance con el que no debía ser.

Al enfrentar el supuesto generador de esta causal a la decisión del amigable componedor, es forzoso concluir que el mismo no podrá darse en esta última, lo que se traduce en que no podrá rescindirse aquella decisión por la causal contemplada en el artículo 2479 del Código Civil. Y es que cuando se está frente a la decisión de un componedor es porque previamente las partes han suscrito un contrato con una disposición puntual que las obligaba ir a la amigable composición; así las cosas, cuando se está frente a una decisión del componedor decir que ha habido un error en la persona es casi como decir que se contrató con la persona equivocada, y en ese caso el error afectaría enteramente al contrato, no a la decisión del amigable componedor.

\section{Rescisión por falta de derecho sobre el objeto}

De acuerdo con la causal contenida en el artículo 2482 del Código Civil, podrá rescindirse la transacción cuando quede demostrado, con títulos auténticos, que una de las partes no tenía ningún derecho sobre el objeto transigido, siempre y cuando la parte a quien favorezca esta rescisión desconociera, al momento de la transacción, los títulos auténticos que demuestran la ausencia de derechos de quien transigió ${ }^{8}$. En esta última hipotesis es necesario que los títulos hubiesen sido escondidos dolosamente por la parte contraria.

Una vez más, para conocer si es o no aplicable en la práctica esta causal a la decisión de la amigable composición se hace necesario trasladar el supuesto fáctico de la disposición al ámbito de la contienda que resuelve un componedor.

\footnotetext{
${ }^{7}$ Artículo 2479 CC

${ }^{8}$ Artículo 2482 CC
}

Justicia Vol. 24 No. 36: pp. 229-239. julio - diciembre, 2019. DOI: 10.17081/just.24.36.3767 
De tal comparación queda en evidencia que, siendo que lo que origina la decisión del componedor es una cláusula contenida en un contrato que a su vez resulta ser el objeto mismo de la contienda, no podría entonces alegarse que una de las partes del contrato, parte también de la decisión, no tenía derecho alguno, toda vez que los derechos que el componedor puede reconocer en su decisión derivan, precisamente, del contrato suscrito por las partes del que deriva la competencia de tal componedor.

\section{EJECUCIÓN DE LA DECISIÓN DEL AMIGABLE COMPONEDOR}

El Estado se abroga para sí la potestad -potestas- de ejecutar todas aquellas decisiones emitidas por órganos que en virtud del ejercicio de la autoridad -autoritas- a ellas dada, resuelven conflictos. La amigable composición no es la excepción, será un juez quien ejecute la decisión del amigable componedor cuando alguna de las partes se lo solicite.

La ejecución de tal composición no escapa a la disposición legal de aplicar a aquella decisión los efectos de la transacción (artículo 60 de la Ley 1563 de 2012); en consecuencia, para conocer cómo se ejecuta es necesario -en primer lugar- estudiar cómo se ejecuta la transacción; y luego, analizar cómo se aplicarían las mismas a la decisión del amigable componedor.

\section{Punto de partida: ejecución de la transacción}

El Estado se ha abrogado para sí la potestad ejecutiva, y esto se traduce en que solo él, por intermedio de los jueces, será quien pueda resolver por medio de un proceso ejecutivo las demandas del mismo tipo.

Si trasladamos lo anterior a la transacción, la conclusión será sencilla: el acuerdo de transacción deberá ejecutarse por la vía de un proceso ejecutivo, conforme las normas del Código General del Proceso, en adelante CGP.

La pregunta que surge a continuación es si el acuerdo de transacción es un título ejecutivo que permite acudir directamente a un proceso de ejecución cuando la transacción es incumplida; o, por el contrario, no lo es y esto supone tener que intentar primero un proceso declarativo que declare incumplida la transacción en una sentencia judicial que preste mérito ejecutivo.

El acuerdo de transacción no es una sentencia judicial

Conforme el artículo 2483 del Código Civil, la transacción es un contrato con un efecto especial: la cosa juzgada, lo que se traduce en que sobre aquel conflicto que desencadenó tal transacción no puede haber un debate judicial en el futuro; en otras palabras, el mismo ha quedado zanjado, no puede volverse a juzgar.

Este efecto es propio de las sentencias y resoluciones judiciales; no es propio de los contratos -es la transacción una excepción-; y por regla general, va acompañado de un segundo efecto que permite materializar tales decisiones: prestan mérito ejecutivo; lo

Justicia Vol. 24 No. 36: pp. 229-239. julio - diciembre, 2019. DOI: 10.17081/just.24.36.3767 
que significa que una vez se dictan y quedan ejecutoriadas, en el juez recae la potestad para hacerlas cumplir.

Esa dupla que en materia de decisiones judiciales existe (cosa juzgada - mérito ejecutivo) puede conllevar a la errónea conclusión de que la transacción goza de las dos. Pero no es así. Cuando se revisan las normas sobre el contrato de transacción en el Código Civil, y el mérito ejecutivo en el CGP, no se encuentra ninguna disposición que indique tal efecto de la transacción, por lo tanto, es un error predicarlo del mismo.

\section{El acuerdo de transacción es un título ejecutivo}

Conforme el artículo 422 del CGP, los títulos ejecutivos son requisito indispensable para intentar un proceso ejecutivo, y pueden constar en distintos documentos: i) en documentos privados donde consten obligaciones claras, expresas y exigibles; ii) en sentencias judiciales de condena; iii) en procesos de policía que apruebe liquidación de costas o señalen honorarios a auxiliares de la justicia; iv) en cualquier otro documento que señale la ley.

El acuerdo de transacción, por su parte, puede encajar por regla general en la primera de las opciones señaladas: la de un documento privado que consagre obligaciones claras, expresas y exigibles, caso en el cual debe intentarse su ejecución por la vía del proceso judicial.

\section{El acuerdo del amigable componedor como título ejecutivo}

Las anteriores disquisiciones en torno al carácter de la transacción y de la vía por medio de la cual debe ejecutarse la misma, son trasladables a la decisión del amigable componedor.

Es la propia ley la que ordena aplicarle a aquella decisión los mismos efectos de una transacción, y en consecuencia deba afirmarse que lo que el componedor resuelve, aunque no es una sentencia porque no presta mérito ejecutivo, si es un título ejecutivo porque su vocación es, precisamente, contener obligaciones claras, expresas y exigibles que resuelvan un conflicto precedente de forma permanente.

\section{Juez competente para ejecutar el acuerdo}

En la Ley 1563 de 2012 no hay una norma de competencia en lo que a la ejecución de la decisión del amigable componedor se refiere, por lo tanto, la ausencia de norma especial de competencia obliga a aplicar las normas de competencia general contempladas en el CGP.

Siendo que a la decisión del amigable componedor hay que mirarla como si fuera una transacción, hay que entender que esa decisión es una decisión con fuerza de cosa juzgada que puede ejecutarse, en pocas palabras, que es un título ejecutivo. 
De acuerdo con el CGP quien pretenda ejecutar un título ejecutivo tendrá que acudir ante el juez civil municipal o al juez civil del circuito, dependiendo de la cuantía del proceso, que irá marcada por el valor del título ejecutivo. Así, si la cuantía fuera mínima o menor el juez competente será el juez civil municipal ${ }^{9}$; si la cuantía fuera mayor, el competente sería el juez civil del circuito ${ }^{10}$.

Por lo tanto, para conocer a qué juez debo dirigir mi demanda ejecutiva cuya pretensión es la ejecución de un acuerdo de un amigable componedor, debo comenzar determinando la cuantía del proceso, de acuerdo al artículo 20 numeral 1 del CGP, y posteriormente definir con base en los artículos 17 y 18 del mismo Código si el competente es el juez civil municipal o el del circuito.

Procedimiento de ejecución del acuerdo

Por tratarse el acuerdo de transacción de un título ejecutivo ${ }^{11}$, quien intente hacerlo efectivo por la vía judicial deberá iniciar un proceso ejecutivo conforme los artículos 422 y siguientes del CGP.

Como todo proceso ejecutivo el interesado presentará una demanda junto con el documento que presta mérito ejecutivo, que en este caso se trataría del acuerdo del amigable componedor, y a continuación el juez librará mandamiento ejecutivo en el que ordene al demandado cumplir con la obligación que surge del título ejecutivo. Contra el mandamiento ejecutivo el demandado podrá interponer recurso de reposición para atacar los requisitos formales del título ejecutivo.

Aterrizando lo anterior a la ejecución del acuerdo del amigable componedor, tenemos que el juez que conozca de una demanda ejecutiva que persigue se ejecute uno de aquellos acuerdos, al momento de decidir si dicta o no un mandamiento ejecutivo debe preocuparse por revisar dos aspectos. El primero y elemental, si el título ejecutivo, en este caso el acuerdo del amigable componedor reúne los requisitos de todo título ejecutivo de acuerdo con el artículo 422 del CGP, estos son: si consagra una o varias obligaciones claras, expresas y exigibles. El segundo y no por ello menos importante, si aquel acuerdo reúne los requisitos de validez ordenados por el Código Civil en el artículo 1502; estos son: que quienes decidieron ir a amigable composición son legalmente capaces, y que su voluntad de resolver sus conflictos por esta vía no estuvo viciada; también que su objeto y causa sean lícitas.

Al hilo de lo que se viene diciendo surge uno de los aspectos más destacados de la solución por la vía de la amigable composición y es aquella que se refiere a que el acuerdo que dicta el amigable componedor no debe ser objeto de control de fondo en sede

\footnotetext{
${ }^{9}$ Artículos 17 y 18 CGP.

${ }^{10}$ Artículo 20 numeral 1 CGP.

${ }^{11}$ Es título ejecutivo en la medida en la que por disposición de la Ley 1563 de 2012 artículo 59, el acuerdo del amigable componedor tiene los efectos de la transacción, y en virtud del artículo 2483 del Código Civil, todo acuerdo de transacción tiene efecto de cosa juzgada en última instancia. Así las cosas, hay que entender que el acuerdo del amigable componedor tiene esos efectos. Y siendo que el artículo 422 del CGP entiende que es título ejecutivo las sentencias de condena o cualquier otra providencia judicial, pues hay que entender que esa decisión del amigable componedor que tiene los mismos efectos que los propios de una decisión judicial, es título ejecutivo.
}

Justicia Vol. 24 No. 36: pp. 229-239. julio - diciembre, 2019. DOI: 10.17081/just.24.36.3767 
judicial. Tampoco le corresponde a quien ejecuta revisar el procedimiento llevado a cabo por el amigable componedor hasta dictar el acuerdo. El juez competente para ejecutar el acuerdo solo puede revisar que el acuerdo reúna los requisitos formales de un título ejecutivo visto supra, así como los requisitos de validez de toda transacción también mencionados antes.

Sin duda, que el procedimiento seguido por el amigable componedor, y el fondo del acuerdo dictado por el mismo no puedan ser objeto de cuestionamiento por parte del juez que ejecuta, es una de las ventajas de la amigable composición frente a otra de las formas heterocompositivas y alternativas para resolver controversias como lo es el arbitraje, que a pesar de ser también de única instancia, el laudo arbitral sí está sometido a un control formal estricto en lo que a procedimiento se refiere, en sede de anulación. Por su parte, y a riesgo de ser reiterativos, la amigable composición no está sujeta a ningún tipo de recurso en el que pueda atacarse el procedimiento y el fondo del acuerdo.

Recapitulando tenemos que una vez el juez competente revise el título ejecutivo acuerdo del amigable componedor- solo analizará si el mismo reúne los requisitos formales de todo título y de validez de toda transacción; si así fuere, dictará mandamiento ejecutivo, de lo contrario, lo negará.

Contra el mandamiento ejecutivo solamente procede el recurso de reposición, tal y como se desprende del artículo 438 del CGP. En la esquina opuesta está el auto que niega total o parcialmente el mandamiento ejecutivo, o el que revoca el mismo por la vía de la reposición, estos sí son apelables.

\section{LA AMIGABLE COMPOSICIÓN SÍ ES UN MECANISMO DE RESOLUCIÓN DE CONFLICTOS EFICAZ}

Por el recelo con el que se puede ver en un principio que el legislador en la Ley 1563 de 2012 ordene aplicarle a la amigable composición los mismos efectos que la transacción, la respuesta a la pregunta de investigación que nos formulamos al inicio de esta investigación sería distinta a la que ahora se expresa en el título de este epígrafe.

Sin embargo, y gracias al estudio detallado de la naturaleza de la decisión del amigable compositor, de cómo se ejecuta y cómo se puede efectuar la oposición a tal decisión, la conclusión a la que arribamos es otra totalmente opuesta: tal y como está hoy en día regulada la amigable composición, este sí resulta ser es un mecanismo efectivo de resolución de conflictos en Colombia.

Ambas, la transacción y la amigable composición están inspiradas en el mismo arranque: un conflicto que se quiere resolver sin la presencia de un juez, de forma definitiva y vinculante; por lo tanto, se entiende completamente que se pueda predicar de ambas la misma forma de ejecución. No interesa si se llama transacción o amigable composición, se entienda que ambas están contenidas en un título ejecutivo toda vez que contiene obligaciones claras, expresas y exigibles, y por tanto está llamado a ser ejecutado por la vía de un proceso judicial.

Al mismo tiempo, ambas tienen como motor la voluntad de las partes, voluntad que debe ser respetada por el operador desde el principio y hasta el final; y de esto es

Justicia Vol. 24 No. 36: pp. 229-239. julio - diciembre, 2019. DOI: 10.17081/just.24.36.3767 
consciente, y sobre todo, garante el legislador, que protege esto precisamente con lo dispuesto en torno a las formas de oponerse que consagra para la transacción, y por remisión a la amigable composición.

\section{REFERENCIAS}

Gil Echeverry, J-H; La conciliación extrajudicial y la amigable composición, Editorial Temis, Bogotá, 2011.

Oñate Acosta, T; Ternera Barrios, F, El contrato sui generis de amigable composición: una alternativa para la solución de controversias en los proyectos de infraestructura, Revista de Derecho Público 35, Julio - Diciembre 2015, Universidad de Los Andes, págs. 4-23.

Rey-Vallejo, Pablo, El arbitraje doméstico colombiano a la sombra de la amigable composición como mecanismo que privilegia la autonomía de la voluntad, Vniversitas 133, Pontificia Universidad Javeriana, págs. 227-270 (2016) 